\title{
Auranofin induces mesothelioma cell death through oxidative stress and GSH depletion
}

\author{
BO RA YOU and WOO HYUN PARK \\ Department of Physiology, Medical School, Institute for Medical Sciences, \\ Chonbuk National University, Jeonju 561-180, Republic of Korea
}

Received August 27, 2015; Accepted October 11, 2015

DOI: $10.3892 /$ or.2015.4382

\begin{abstract}
Mesothelioma is an aggressive tumor associated with asbestos exposure. Auranofin as an inhibitor of thioredoxin reductase (TrxR) affects many biological processes such as inflammation and proliferation. In the present study, we investigated the cellular effects of auranofin on patient-derived mesothelioma cells in relation to reactive oxygen species (ROS) and glutathione (GSH) levels. Basal TrxR1 levels have no difference between mesothelial cells and certain mesothelioma cells. In particular, ADA, CON and Hmeso mesothelioma cells showed lower levels of TrxR1 expression. Auranofin inhibited the proliferation of mesothelioma cells in a dose-dependent manner. Among mesothelioma cells were ADA and CON cells sensitive to auranofin. This agent also induced caspase-independent apoptosis and necrosis in ADA cells. In addition, auranofin increased ROS levels including $\mathrm{O}_{2}^{-}$and induced GSH depletion in mesothelioma cells. While N-acetyl cysteine (NAC) prevented cell death and decreased ROS levels in auranofin-treated mesothelioma cells, L-buthionine sulfoximine (BSO) intensified apoptosis and GSH depletion in these cells. In conclusion, auranofin induced mesothelioma cell death through oxidative stress and the death was regulated by the status of GSH content.
\end{abstract}

Correspondence to: Professor Woo Hyun Park, Department of Physiology, Medical School, Institute for Medical Sciences, Chonbuk National University, Jeonju 561-180, Republic of Korea E-mail: parkwh71@chonbuk.ac.kr

Abbreviations: Trx R, thioredoxin reductase; ROS, reactive oxygen species; GSH, glutathione; NADPH, nicotinamide adenine dinucleotide phosphate; $\operatorname{MMP}\left(\Delta \Psi_{\mathrm{m}}\right)$, mitochondrial membrane potential; FBS, fetal bovine serum; MTT, 3-(4,5-dimethylthiazol2-yl)-2,5-diphenyltetrazolium bromide; PI, propidium iodide; NAC, $\mathrm{N}$-acetylcysteine; BSO, L-buthionine sulfoximine; LDH, lactate dehydrogenase; $\mathrm{H}_{2}$ DCFDA, 2',7'-dichlorodihydrofluorescein diacetate; DHE, dihydroethidium; FITC, fluorescein isothiocyanate; GSH, glutathione; CMFDA, 5-chloromethylfluorescein diacetate; Z-VAD-FMK, benzyloxycarbonyl-Val-Ala-Asp-fluoromethylketone;

Key words: mesothelioma, auranofin, reactive oxygen species, thioredoxin reductas, glutathione

\section{Introduction}

Thioredoxin (Trx) and glutathione (GSH) are major antioxidant systems in the cells to defend excess reactive oxygen species (ROS) production. Trx system consists of Trx and nicotinamide adenine dinucleotide phosphate (NADPH)-dependent Trx reductase (TrxR) (1). Trx, having two active sites in cysteine residue, exists as a dithiol, reduced form. When Trx is oxidized, it is reduced by $\operatorname{TrxR}(1)$. GSH is a non-protein antioxidant and stabilizes the oxidized molecules by supplying electron. Trx and GSH systems control not only redox status but also affect many cellular events such as proliferation and apoptosis (2-4). Especially, TrxR1 is overexpressed in breast and oral cancer patients $(5,6)$. It has been reported that the inhibition of TrxR increases the sensitivity of cancer cells to radiotherapy and anticancer drugs in melanoma, colon and breast cancers (7-9). Therefore, the regulation of Trx system can be a promising target for cancer therapy (10).

Auranofin, as a TrxR inhibitor, is used for the treatment of rheumatoid arthritis. Originally, this agent was considered as anti-inflammatory drug (11). However, recently many studies demonstrate that auranofin has an anticancer effect in leukemia and ovarian cancer cells $(12,13)$. In addition, It has been suggested that auranofin induces FOXO3 activation, ROS accumulation, DNA damage and ERK inactivation in cancer cells $(13,14)$. Mesothelioma is a rare tumor mainly derived from the pleura of lung and it has a poor prognosis (15). Although it is reported that TrxR1 is overexpressed in mesothelioma cells (16), little is known about the anti-growth effect of auranofin in mesothelioma cells.

In the present study, we investigated the effects of auranofin on cell proliferation and death in patient-derived human mesothelioma cells in relation to ROS and GSH levels.

\section{Materials and methods}

Cell culture. Human mesothelial cells (HM69 and HM72) and human mesothelioma cells (ADA, CON, Hmeso, Mill, Phi, REN and ROB) were obtained from Queen's Medical Center (Honolulu, HI, USA). These cells were cultured in Ham's F-12 media containing $10 \%$ fetal bovine serum (FBS) and $1 \%$ penicillin-streptomycin (both from Gibco BRL, Grand Island, NY, USA). Mesothelial and mesothelioma cells were maintained in incubator containing $5 \% \mathrm{CO}_{2}$ at $37^{\circ} \mathrm{C}$. Cells were grown in 
$100 \mathrm{~mm}$ plastic cell culture dishes (BD Falcon, Franklin Lakes, NJ, USA) and harvested with a trypsin-EDTA (Gibco BRL).

Reagents. Auranofin purchased from Santa Cruz Biotechnology (Santa Cruz, CA, USA) was dissolved in dimethyl sulfoxide (DMSO; Sigma-Aldrich Chemical Co., St. Louis, MO, USA) at $10 \mathrm{mM}$ as a stock solution. The pan-caspase inhibitor (Z-VAD-FMK; benzyloxycarbonyl-Val-Ala-Asp-fluoromethylketone) was obtained from R\&D Systems, Inc. (Minneapolis, MN, USA) and were dissolved in DMSO at $10 \mathrm{mM}$. NecroX-2 and necrostatin-1 from Enzo Life Science (Plymouth Meeting, PA, USA) were dissolved in DMSO at 1 and $50 \mathrm{mM}$, respectively. NAC and BSO obtained from Sigma-Aldrich Chemical Co. were dissolved in $20 \mathrm{mM}$ HEPES (pH 7.0) and water at $100 \mathrm{mM}$, respectively. Cells were pretreated with $15 \mu \mathrm{M}$ Z-VAD, $1 \mu \mathrm{M}$ NecroX-2, $50 \mu \mathrm{M}$ necrostatin-1, $2 \mathrm{mM}$ NAC or $10 \mu \mathrm{M}$ BSO for $1 \mathrm{~h}$ prior to auranofin treatment.

Western blot analysis. The protein expression levels were evaluated by western blot analysis. In brief, $1 \times 10^{6}$ cells in $60 \mathrm{~mm}$ culture dish (BD Falcon) were incubated with or without $3 \mu \mathrm{M}$ auranofin for $24 \mathrm{~h}$. Then cells were washed with phosphate-buffered saline (PBS) and added in 4 volumes of protein extract buffer (Life Technologies, Carlsbad, CA, USA). The concentrations of protein were determined using the Bradford method. A total of $30 \mu \mathrm{g}$ total proteins were resolved by 4-20\% SDS-PAGE gels, and then transferred to Immobilon-P PVDF membranes (Millipore, Billerica, MA, USA) by electroblotting. Then membranes were probed with anti-PARP and anti-c-PARP (Cell signaling Technology, Danvers, MA, USA) and anti-TrxR1, anti-GAPDH and anti- $\beta$-actin (Santa Cruz Biotechnology). Membrane was incubated with fluorescence-conjugated secondary antibodies. Bands were visualized by using a LI-COR Odyssey Imager (LI-COR Biosciences, Lincoln, NE, USA).

Cell proliferation assay. The effect of auranofin on proliferation in mesothelioma cells was determined by CellTiter $96^{\circledR} \mathrm{AQ}_{\text {ueous }}$ Non-Radioactive Cell Proliferation Assay kit (Promega, Madison, WI, USA). In brief, $5 \times 10^{3}$ cells in 96-well microtiter plate (BD Falcon) were incubated with the indicated concentrations of auranofin with or without NAC or BSO for $24 \mathrm{~h}$. Then, $20 \mu \mathrm{l}$ of 3-(4,5-dimethylthazol-2-yl)-5-(3-carboxy methoxyphenyl)-2-(4-sulfophenyl)-2H-tetrazolium (MTS) and phenazine methosulfate (PMS) mixture was added to each well in 96-well plates. The plates were incubated for $3 \mathrm{~h}$ at $37^{\circ} \mathrm{C}$. The optical density was measured at $490 \mathrm{~nm}$ using a microplate reader (VersaMax plate reader; Molecular Devices, Sunnyvale, CA, USA).

Sub G-1 analysis. Sub-G1 analysis was determined by propidium iodide (PI; Sigma-Aldrich Chemical Co.; $\mathrm{Ex} / \mathrm{Em}=488 / 617 \mathrm{~nm}$ ) staining. Briefly, $1 \times 10^{6}$ cells in $60 \mathrm{~mm}$ culture dish (BD Falcon) were incubated with the indicated concentrations of auranofin with or without Z-VAD, NecroX-2 or necrostatin-1 for $24 \mathrm{~h}$. Cells were washed with PBS and then incubated with $10 \mu \mathrm{g} / \mathrm{ml}$ PI with RNase at $37^{\circ} \mathrm{C}$ for $30 \mathrm{~min}$. Sub-G1 DNA content cells were analyzed with an Accuri C6 flow cytometer (BD Sciences, Franklin Lakes, NJ, USA).
Annexin V/PI staining. Apoptosis was detected by staining cells with Annexin V-fluorescein isothiocyanate (FITC; Life Technologies; Ex/Em=488/519 nm) and PI (Sigma-Aldrich Chemical Co.). Briefly, $1 \times 10^{6}$ cells in $60 \mathrm{~mm}$ culture dish (BD Falcon) were incubated with the indicated concentrations of auranofin with or without Z-VAD, NecroX-2, necrostatin-1, NAC or BSO for $24 \mathrm{~h}$. Then cells were washed twice with cold PBS and added $500 \mu \mathrm{l}$ of binding buffer $(10 \mathrm{mM}$ HEPES/NaOH $\mathrm{pH} 7.4,140 \mathrm{mM} \mathrm{NaCl}, 2.5 \mathrm{mM} \mathrm{CaCl}$ ) at a concentration of $1 \times 10^{6}$ cells $/ \mathrm{ml}$. Five microliters of Annexin V-FITC and PI were added to these cells, which were analyzed with Accuri C6 flow cytometer (BD Sciences).

Lactate dehydrogenase $(L D H)$ release assay. Necrosis in cells was evaluated by LDH kit (Sigma-Aldrich Chemical Co.) Briefly, $1 \times 10^{6}$ cells in $60 \mathrm{~mm}$ culture dish (BD Falcon) were incubated with the indicated concentration of auranofin with or without NAC or BSO for $24 \mathrm{~h}$. After treatment, the cell culture media were collected and centrifuged for $5 \mathrm{~min}$ at $1,500 \mathrm{rpm}$. A total of $50 \mu \mathrm{l}$ of the media supernatant was added to a fresh 96-well plate (SPL Life Sciences, Pocheon, Gyeonggi-do, Korea) with $\mathrm{LDH}$ assay reagent and then incubated at room temperature for $30 \mathrm{~min}$. The absorbance values were measured at $490 \mathrm{~nm}$ using a microplate reader (Synergy $^{\text {TM }}$ 2; BioTek ${ }^{\circledR}$ Instruments Inc., Winooski, VT, USA). $\mathrm{LDH}$ release was expressed as the percentage of extracellular LDH activity compared with the control cells.

Detection of intracellular ROS levels. Intracellular ROS such as $\mathrm{H}_{2} \mathrm{O}_{2},{ }^{\circ} \mathrm{OH}$ and $\mathrm{ONOO}{ }^{\circ}$ were detected by an oxidation-sensitive fluorescent probe dye, 2',7'-dichlorodihydrofluorescein diacetate $\left(\mathrm{H}_{2} \mathrm{DCFDA}\right.$, Life Technologies; Ex/Em=495/529 nm). As $\mathrm{H}_{2}$ DCFDA is poorly selective for $\mathrm{O}_{2}{ }^{-}$, dihydroethidium (DHE, Life Technologies; Ex/Em=518/605 nm), which is highly selective for $\mathrm{O}_{2}^{\circ-}$, was used for its detection. Briefly, $1 \times 10^{6}$ cells in $60 \mathrm{~mm}$ culture dish (BD Falcon) were incubated with the indicated concentrations of auranofin with or without NAC or BSO for $24 \mathrm{~h}$. The cells were washed in PBS and incubated with $20 \mu \mathrm{M} \mathrm{H}_{2}$ DCFDA and DHE at $37^{\circ} \mathrm{C}$ for $30 \mathrm{~min}$. DCF and DHE fluorescences were detected by using Accuri C6 flow cytometer (BD Sciences).

Measurement of intracellular GSH level. Cellular GSH levels were analyzed using a 5-chloromethylfluorescein diacetate dye (CMFDA, Ex/Em=522/595 nm; Life Technologies). In brief, $1 \times 10^{6}$ cells were incubated in a $60 \mathrm{~mm}$ culture dishes (BD Falcon) with $3 \mu \mathrm{M}$ auranofin with or without NAC or BSO for $24 \mathrm{~h}$. Cells were then washed with PBS and incubated with $5 \mu \mathrm{M}$ CMFDA at $37^{\circ} \mathrm{C}$ for $30 \mathrm{~min}$. CMF fluorescence intensity was determined using Accuri C6 flow cytometer (BD Sciences). Negative CMF staining (GSH-depletion) of cells is expressed as the percentage of (-) CMF cells.

Statistical analysis. The results represent the mean of at least three independent experiments (mean $\pm \mathrm{SD}$ ). Data were analyzed using Instat software (GraphPad Prism4, San Diego, CA, USA). The Student's t-test or one-way analysis of variance (ANOVA) with post hoc analysis using Tukey's multiple comparison test was used for parametric data. $\mathrm{P}<0.05$ was considered to indicate a statistically significant difference. 
B

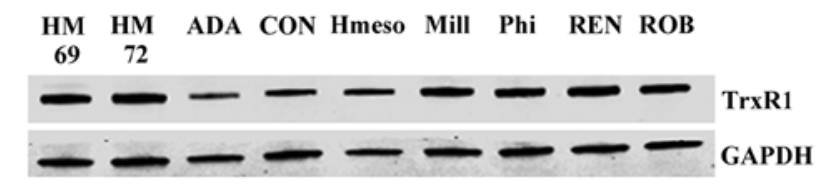

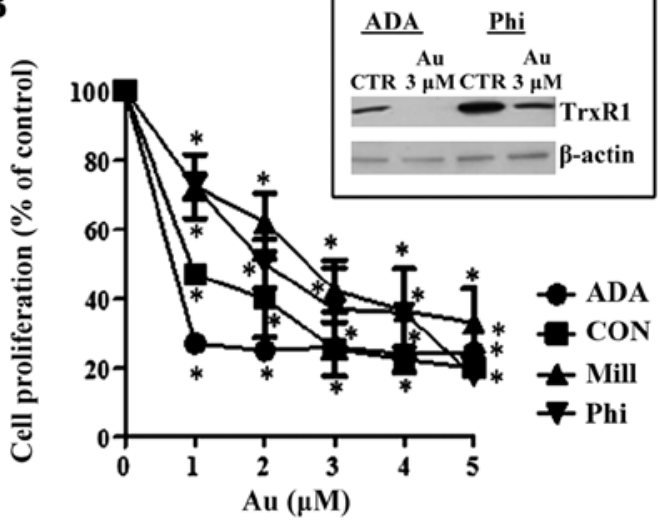

C

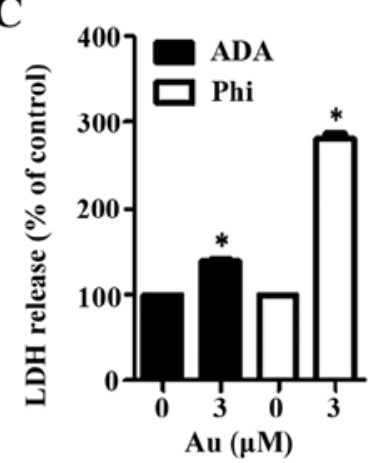

D

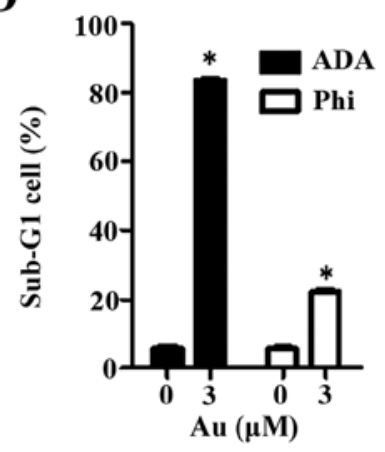

$\mathbf{E}$

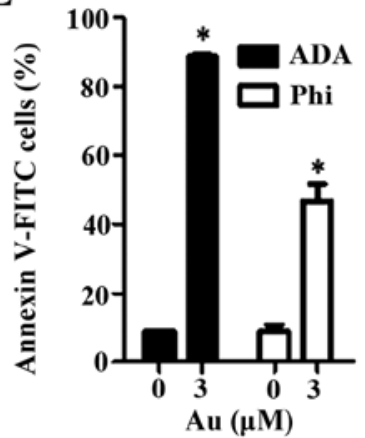

$\mathbf{F}$

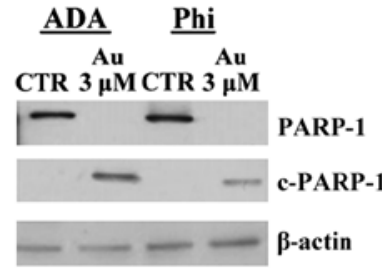

Figure 1. Effects of auranofin on proliferation and death in mesothelioma cells. (A) The expression levels of TrxR1 proteins were examined by western blot analysis. Exponentially growing cells were treated with the indicated concentrations of auranofin for $24 \mathrm{~h}$. The expression levels of TrxR1 and GAPDH in mesothelial and mesothelioma cells. (B) Cell proliferations were assessed by MTS assay. The insert image indicates the expression of TrxR1 and $\beta$-actin in ADA and Phi cells. (C) The graph shows LDH release. (D and E) The graphs show sub-G1 cells (D) and Annexin V-FITC positive cells (E). (F) The expression of PARP and c-PARP was examined by western blot analysis. ${ }^{*} \mathrm{P}<0.05$ compared with auranofin-untreated control group.

\section{Results}

Auranofin inhibits proliferation and induces the death of mesothelioma cells. Firstly, we observed the protein expression levels of TrxR1 in human mesothelial and mesothelioma cells. As a result, there was no difference of TrxR1 expression in either mesothelial or mesothelioma cells (Fig. 1A). Instead, the levels of TrxR1 in ADA, CON and Hmeso were lower than those in other mesothelioma cells (Fig. 1A). Treatment with auranofin attenuated the proliferation of mesothelioma cells in a dose-dependent manner (Fig. 1B). ADA and CON cells, which showed lower TrxR1 levels, were more sensitive to auranofin than Mill and Phi cells (Fig. 1B). Auranofin completely reduced the level of TrxR1 in ADA cells and this agent also decreased that of Phi cells (Fig. 1B). In addition, auranofin increased LDH release, sub-G1 cells and Annexin V positive cells in ADA and Phi cells (Fig. 1C-E). LDH release was high in Phi cells whereas sub-G1 cells and Annexin V positive cells were high in ADA cells. It also induced a cleavage in PARP protein in ADA and Phi cells (Fig. 1F).

Auranofin leads to necrosis in ADA cells. It was investigated whether auranofin induces apoptosis and/or necrosis in ADA cells. When auranofin-treated ADA cells were co-incubated with Z-VAD, a pan-caspase inhibitor, Z-VAD did not change the percentages of sub-G1 and Annexin $V$ positive cells in these cells (Fig. 2A and B). In contrast, NecroX-1, necrosis inhibitor, decreased the numbers of sub-G1 and Annexin V positive cells in auranofin-treated ADA cells and necrostatin-1, necroptosis inhibitor, reduced the numbers of decreased sub-G1 and Annexin $\mathrm{V}$ positive cells in these cells as well (Fig. 2C and D).

NAC prevents auranofin-induced cell death in ADA and Phi cells. Auranofin is an inhibitor of TrxR1. Therefore, it can induce cell death through an oxidative stress. We pre-treated ADA and Phi cells with $2 \mathrm{mM} \mathrm{NAC}$ for $1 \mathrm{~h}$ prior to the treatment of auranofin. NAC significantly recovered the reduced cell proliferation caused by auranofin in ADA and Phi cells (Fig. 3A). NAC also inhibited auranofin-induced LDH release in both cells (Fig. 3B). NAC significantly prevented cell death in auranofin-treated ADA and Phi cells, and the prevention was dramatic in ADA cells (Fig. 3C). As expected, auranofin increased ROS levels including $\mathrm{O}_{2}{ }^{-}$in ADA and Phi cells at $24 \mathrm{~h}$, and NAC decreased the levels in these cells (Fig. 4A and B). Auranofin also induced GSH depletion in ADA and Phi cells (Fig. 4C and D). NAC completely blocked the GSH depletion caused by auranofin in ADA and Phi cells (Fig. 4C and D).

BSO enhances auranofin-induced cell death in ADA and Phi cells. There are two main antioxidant systems, Trx and GSH in cells. For this reason, inhibition of GSH synthesis might be a novel strategy to disturb the redox status and finally lead to cell death. As expected, BSO intensified the inhibition of cell proliferation in Phi cells, which were relatively resistant to auranofin compared with ADA cells (Fig. 3A). BSO did not 

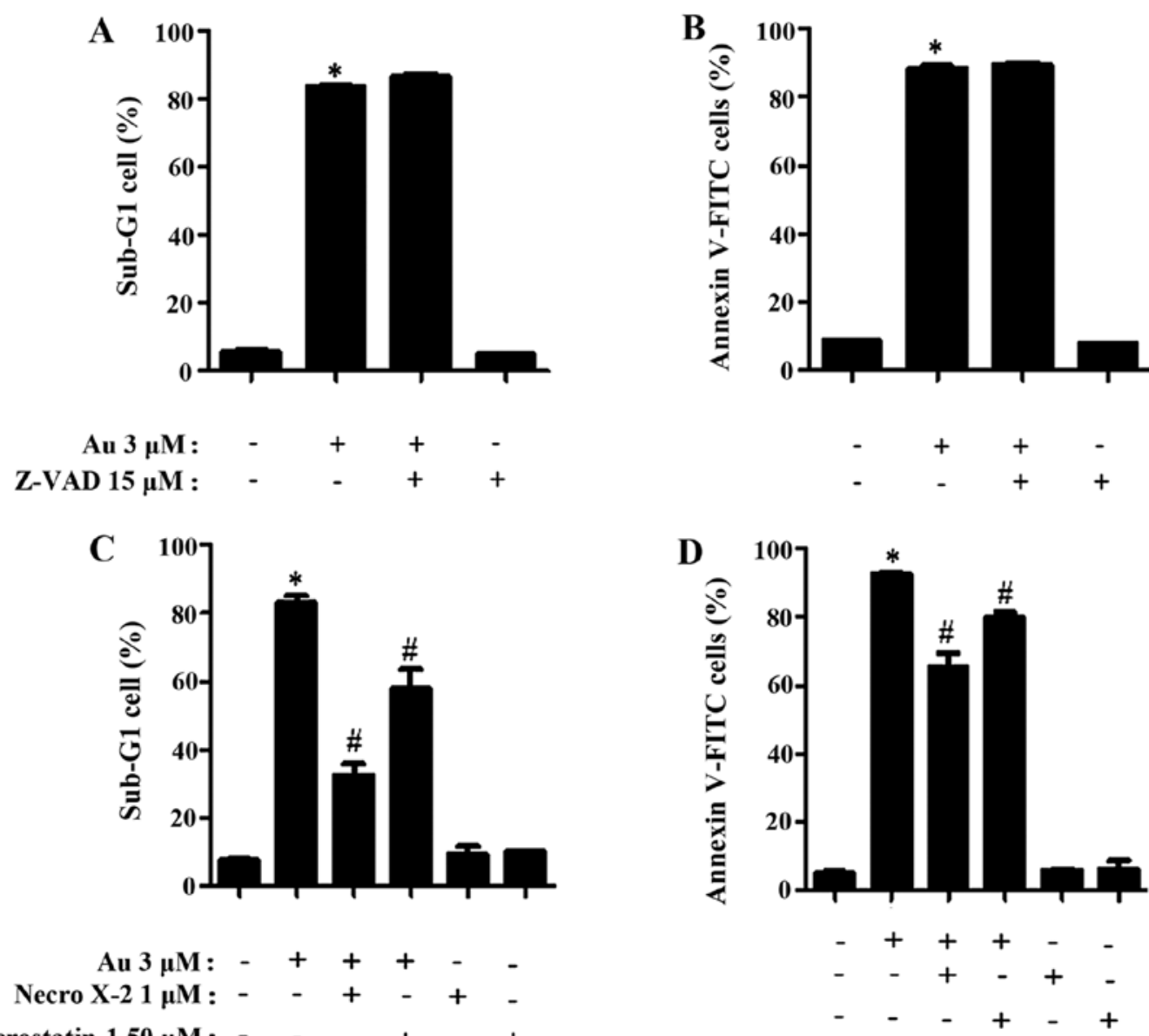

Figure 2. Effects of Z-VAD, NecroX-2 and necrostatin-1 on apoptosis and necrosis in auranofin-treated ADA cells. Exponentially growing cells were treated with $3 \mu \mathrm{M}$ auranofin in the presence or absence of $15 \mu \mathrm{M}$ Z-VAD, $1 \mu \mathrm{M}$ NecroX-2 and $50 \mu \mathrm{M}$ necrostatin-1 for $24 \mathrm{~h}$. (A and C) The graphs show sub-G1 cells. (B and D) The graphs show Annexin V-FITC positive cells. ${ }^{*} \mathrm{P}<0.05$ compared with auranofin-untreated control group. ${ }^{\prime \prime} \mathrm{P}<0.05$ compared with cells treated with auranofin only.

additionally increase the LDH release in auranofin-treated ADA and Phi cells (Fig. 3B). However, BSO significantly increased apoptotic cell death in auranofin-treated ADA and Phi cells (Fig. 3C). BSO also augmented the increased ROS levels including $\mathrm{O}_{2}^{-}$in auranofin-treated cells and the augmentation was strong in Phi cells (Fig. 4A and B). Moreover, BSO significantly increased the numbers of GSH-depleted cells in auranofin-treated Phi cells (Fig. 4D).

\section{Discussion}

Auranofin as an inhibitor of TrxR has an anti-inflammatory effect (17) and can treat rheumatoid arthritis (18). In addition, auranofin shows anticancer effects in ovarian, prostate, breast and lung cancer cells (14,19-21). It is also reported that many cancer cells contain high level of TrxR expression $(6,22)$. Thus, auranofin can be a strong candidate agent for treatment of cancer. Likewise, in the present study, auranofin inhibited the proliferation in mesothelioma cells and induced caspase-independent apoptosis and necrosis in these cells. Interestingly, the basal TrxR1 expression levels were not different between normal mesothelial cells and mesothelioma cells. This result is contrary to the report that $\operatorname{Trx}$ and $\operatorname{Trx} \mathrm{R}$ were upregulated in mesothelioma (16). This discrepancy will be clarified in relation to expression and activity in $\operatorname{Trx}$ and $\operatorname{Trx} \mathrm{R}$ proteins between normal and cancer cells. We observed that ADA and CON cells showed low level of TrxR1 expression and these cells were more sensitive to auranofin than other mesothelioma cells. These results support that the level of TrxR1 expression is involved in the cytotoxic effectiveness of drug among cancer cells (23).

Excess ROS production or an imbalance of antioxidant can lead to oxidative stress and finally damages the cells (24). Trx and GSH are the two main antioxidant systems in the cells (25). TrxR is a key component in the Trx system. Therefore, an inhibition of $\operatorname{Trx} R$ can induce cell death via causing oxidative stress (26). Correspondingly, auranofin increased the ROS levels including $\mathrm{O}_{2}^{--}$in relatively auranofin-sensitive ADA cells and auranofin-resistant Phi cells. An increase in ROS levels was strong in Phi cells. This result suggests that auranofin-resistant Phi cells have a high threshold to oxidative stress to induce cell death. Furthermore, NAC, an antioxidant, attenuated the inhibition of proliferation in auranofin-treated ADA and Phi cells. This agent also prevented cell death in these cells. The prevention was accompanied by a decrease in ROS levels. These results suggest that auranofin induce cell growth inhibition and cell death in an oxidative stress-dependent manner. 


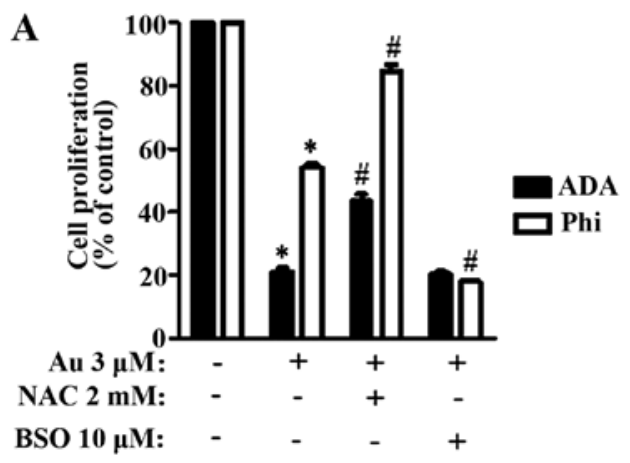

C

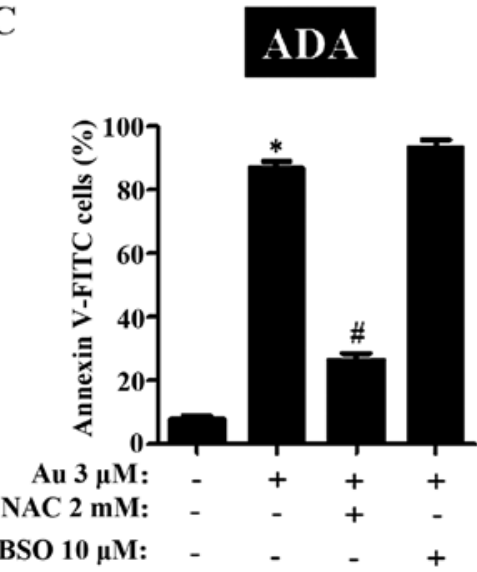

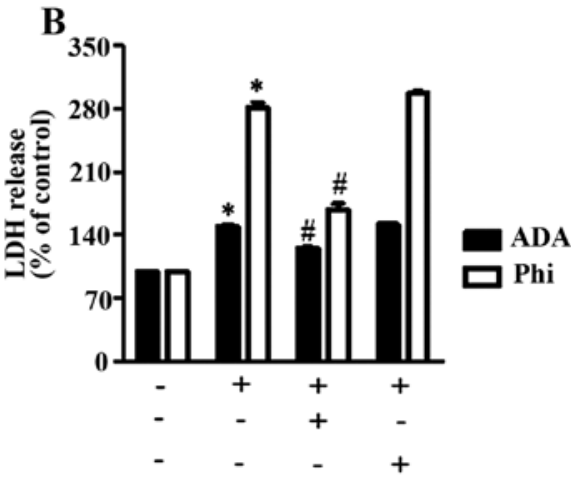

D
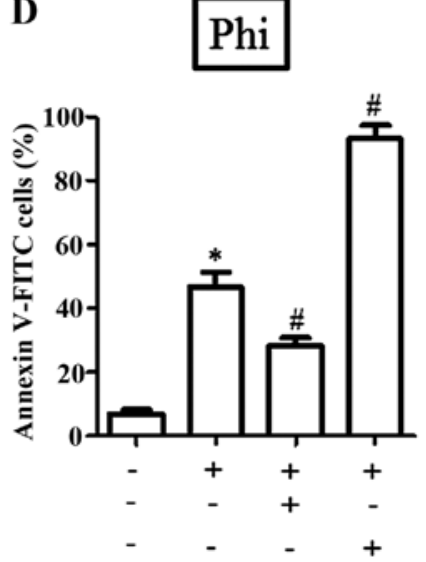

Figure 3. Effects of NAC and BSO on proliferation and cell death in auranofin-treated ADA and Phi cells. Exponentially growing cells were treated with $3 \mu \mathrm{M}$ auranofin in the presence or absence $2 \mathrm{mM} \mathrm{NAC}$ and $10 \mu \mathrm{M}$ BSO for $24 \mathrm{~h}$. The graphs show cell proliferation (A) and LDH release (B). (C and D) The graphs show Annexin V-FITC/PI staining cells. "P $<0.05$ compared with auranofin-untreated control group. ${ }^{*} \mathrm{P}<0.05$ compared with cells treated with auranofin only.
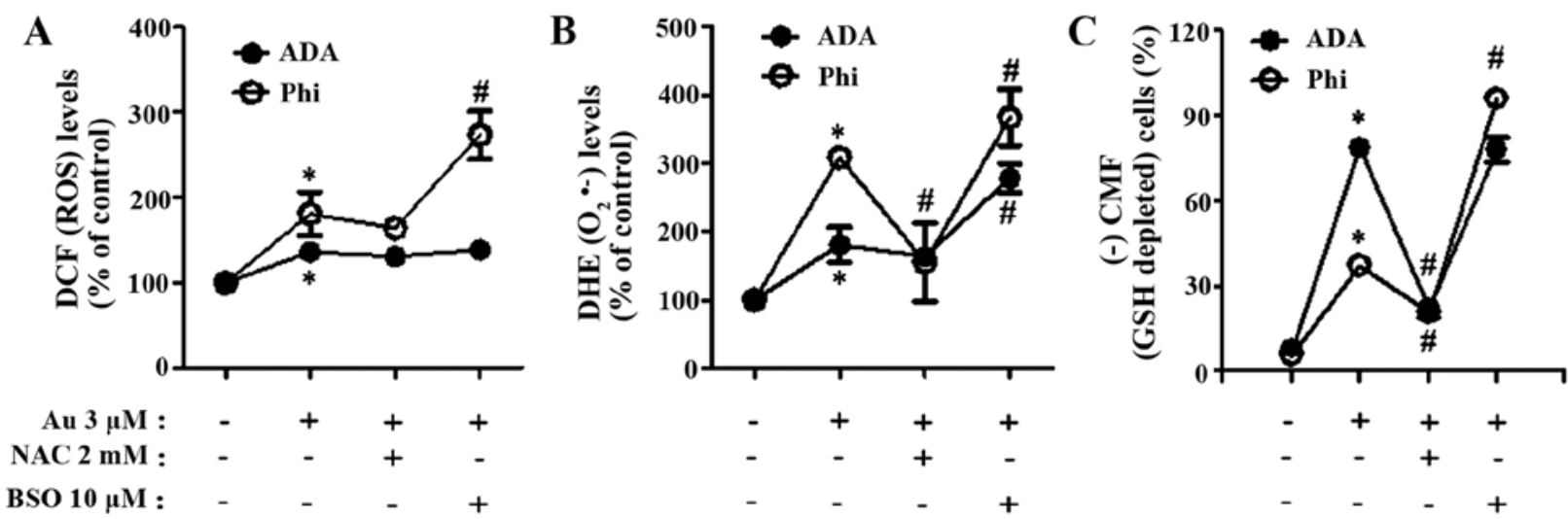

Figure 4. Effects of NAC and BSO on intracellular ROS levels and GSH depletion in auranofin-treated ADA and Phi cells. Exponentially growing cells were treated with $3 \mu \mathrm{M}$ auranofin in the presence or absence $2 \mathrm{mM}$ NAC and $10 \mu \mathrm{M}$ BSO for $24 \mathrm{~h}$. The graphs indicate DCF (ROS) levels (A) and DHE ( ${ }_{2}^{\circ}$ ) levels (B). (C) The graph shows the percent of (-) CMF (GSH-depleted) cells. " $\mathrm{P}<0.05$ compared with auranofin-untreated control group. " $\mathrm{P}<0.05$ compared with cells treated with auranofin only.

GSH is a non-protein antioxidant and prevents cells from damage caused by oxidative stress (27). The thiol group of cysteine in GSH supplies an electron to unstable molecules and then GSH itself is oxidized. When GSH is converted to oxidized-form, it is reduced back by GSH reductase $(28,29)$. GSH is also critical for cell proliferation and apoptosis $(30,31)$. Therefore, an inhibition of GSH is a reasonable strategy to enhance cytotoxicity in anticancer drug resistant cancer cells (32). Likewise, auranofin increased the depletion of GSH in both ADA and Phi cells. Auranofin-sensitive ADA cells showed a strong depletion in GSH content. NAC significantly blocked GSH depletion in auranofin-treated ADA and Phi cells. Thus, NAC plays a role as a precursor of GSH as well as an antioxidant in mesothelioma cells. BSO, an inhibitor of GSH synthesis, intensified cell growth inhibition and cell death in auranofin-treated ADA and Phi cells. The enhancement of cell death by BSO was remarkable in auranofin-resistant Phi cells. BSO also accelerated the increase in ROS level and 
GSH depletion in auranofin-treated Phi cells. These results demonstrated that an inhibition of GSH is effective to enhance cell growth inhibition and cell death in auranofin-resistant mesothelioma cells.

In conclusion, it is the first report that auranofin inhibited cell proliferation in mesothelioma cells and induced cell death in these cells through an oxidative stress. In addition, mesothelioma cell death caused by auranofin was affected by the status of GSH content.

\section{Acknowledgements}

We thank Professor Peter R. Hoffmann and Dr Pietro Bertino for kindly providing the mesothelioma cells. The present study was supported by the National Research Foundation of Korea (NRF) grant funded by the Korea government (MSIP) (no. 2008-0062279) and supported by the Basic Science Research Program through the NRF funded by the Ministry of Education (2013006279).

\section{References}

1. Lu J and Holmgren A: The thioredoxin antioxidant system. Free Radic Biol Med 66: 75-87, 2014.

2. Chen B, Nelin VE, Locy ML, Jin Y and Tipple TE: Thioredoxin-1 mediates hypoxia-induced pulmonary artery smooth muscle cell proliferation. Am J Physiol Lung Cell Mol Physiol 305: L389-L395, 2013.

3. Bobba A, Casalino E, Petragallo VA and Atlante A: Thioredoxin/thioredoxin reductase system involvement in cerebellar granule cell apoptosis. Apoptosis 19: 1497-1508, 2014.

4. Laborde E: Glutathione transferases as mediators of signaling pathways involved in cell proliferation and cell death. Cell Death Differ 17: 1373-1380, 2010.

5. Cadenas C, Franckenstein D, Schmidt M, Gehrmann M, Hermes M, Geppert B, Schormann W, Maccoux LJ, Schug M, Schumann A, et al: Role of thioredoxin reductase 1 and thioredoxin interacting protein in prognosis of breast cancer. Breast Cancer Res 12: R44, 2010.

6. Iwasawa S, Yamano Y, Takiguchi Y, Tanzawa H, Tatsumi K and Uzawa K: Upregulation of thioredoxin reductase 1 in human oral squamous cell carcinoma. Oncol Rep 25: 637-644, 2011.

7. Fu JN, Li J, Tan Q, Yin HW, Xiong K, Wang TY, Ren XY and Zeng HH: Thioredoxin reductase inhibitor ethaselen increases the drug sensitivity of the colon cancer cell line LoVo towards cisplatin via regulation of $\mathrm{G} 1$ phase and reversal of $\mathrm{G} 2 / \mathrm{M}$ phase arrest. Invest New Drugs 29: 627-636, 2011.

8. Lin T, Ding Z, Li N, Xu J, Luo G, Liu J and Shen J: 2 -Tellurium-bridged $\beta$-cyclodextrin, a thioredoxin reductase inhibitor, sensitizes human breast cancer cells to TRAIL-induced apoptosis through DR5 induction and NF- $\mathrm{KB}$ suppression. Carcinogenesis 32: 154-167, 2011.

9. Liang YW, Zheng J, Li X, Zheng W and Chen T: Selenadiazole derivatives as potent thioredoxin reductase inhibitors that enhance the radiosensitivity of cancer cells. Eur J Med Chem 84: 335-342, 2014.

10. Kiebala M, Skalska J, Casulo C, Brookes PS, Peterson DR, Hilchey SP, Dai Y, Grant S, Maggirwar SB and Bernstein SH: Dual targeting of the thioredoxin and glutathione antioxidant systems in malignant B cells: A novel synergistic therapeutic approach. Exp Hematol 43: 89-99, 2015.

11. Isakov E, Weisman-Shomer $P$ and Benhar M: Suppression of the pro-inflammatory NLRP3/interleukin- $1 \beta$ pathway in macrophages by the thioredoxin reductase inhibitor auranofin. Biochim Biophys Acta 1840: 3153-3161, 2014.

12. Liu N, Li X, Huang H, Zhao C, Liao S, Yang C, Liu S, Song W, Lu X, Lan X, et al: Clinically used antirheumatic agent auranofin is a proteasomal deubiquitinase inhibitor and inhibits tumor growth. Oncotarget 5: 5453-5471, 2014.

13. Park SH, Lee JH, Berek JS and Hu MC: Auranofin displays anticancer activity against ovarian cancer cells through FOXO3 activation independent of p53. Int J Oncol 45: 1691-1698, 2014.
14. Fan C, Zheng W, Fu X, Li X, Wong YS and Chen T: Enhancement of auranofin-induced lung cancer cell apoptosis by selenocystine, a natural inhibitor of TrxR1 in vitro and in vivo. Cell Death Dis 5: e1191, 2014.

15. Mansfield AS, Roden AC, Peikert T, Sheinin YM, Harrington SM, Krco CJ, Dong H and Kwon ED: B7-H1 expression in malignant pleural mesothelioma is associated with sarcomatoid histology and poor prognosis. J Thorac Oncol 9: 1036-1040, 2014.

16. Kahlos K, Soini Y, Säily M, Koistinen P, Kakko S, Pääkkö P, Holmgren A and Kinnula VL: Up-regulation of thioredoxin and thioredoxin reductase in human malignant pleural mesothelioma. Int J Cancer 95: 198-204, 2001.

17. Han S, Kim K, Kim H, Kwon J, Lee YH, Lee CK, Song Y, Lee SJ, Ha N and Kim K: Auranofin inhibits overproduction of pro-inflammatory cytokines, cyclooxygenase expression and PGE2 production in macrophages. Arch Pharm Res 31: 67-74, 2008.

18. Suarez-Almazor ME, Spooner $\mathrm{CH}$, Belseck E and Shea B: Auranofin versus placebo in rheumatoid arthritis. Cochrane Database Syst Rev 2: CD002048, 2000.

19. Kim NH, Park HJ, Oh MK and Kim IS: Antiproliferative effect of gold(I) compound auranofin through inhibition of STAT3 and telomerase activity in MDA-MB 231 human breast cancer cells. BMB Rep 46: 59-64, 2013.

20. Park N and Chun YJ: Auranofin promotes mitochondrial apoptosis by inducing annexin A5 expression and translocation in human prostate cancer cells. J Toxicol Environ Health A 77: 1467-1476, 2014.

21. Papaioannou M, Mylonas I, Kast RE and Brüning A: Disulfiram/copper causes redox-related proteotoxicity and concomitant heat shock response in ovarian cancer cells that is augmented by auranofin-mediated thioredoxin inhibition. Oncoscience 1: 21-29, 2014.

22. Lincoln DT, Al-Yatama F, Mohammed FM, Al-Banaw AG, Al-Bader M, Burge M, Sinowatz F and Singal PK: Thioredoxin and thioredoxin reductase expression in thyroid cancer depends on tumour aggressiveness. Anticancer Res 30: 767-775, 2010.

23. Eriksson SE, Prast-Nielsen S, Flaberg E, Szekely L and Arnér ES: High levels of thioredoxin reductase 1 modulate drug-specific cytotoxic efficacy. Free Radic Biol Med 47: 1661-1671, 2009.

24. Ferrer MD, Sureda A, Tauler P, Palacín C, Tur JA and Pons A: Impaired lymphocyte mitochondrial antioxidant defences in variegate porphyria are accompanied by more inducible reactive oxygen species production and DNA damage. Br J Haematol 149: 759-767, 2010.

25. Scarbrough PM, Mapuskar KA, Mattson DM, Gius D, Watson WH and Spitz DR: Simultaneous inhibition of glutathione- and thioredoxin-dependent metabolism is necessary to potentiate 17AAG-induced cancer cell killing via oxidative stress. Free Radic Biol Med 52: 436-443, 2012.

26. Lopert P, Day BJ and Patel M: Thioredoxin reductase deficiency potentiates oxidative stress, mitochondrial dysfunction and cell death in dopaminergic cells. PLoS One 7: e50683, 2012.

27. Dunning S, Ur Rehman A, Tiebosch MH, Hannivoort RA, Haijer FW, Woudenberg J, van den Heuvel FA, Buist-Homan M, Faber KN and Moshage $\mathrm{H}$ : Glutathione and antioxidant enzymes serve complementary roles in protecting activated hepatic stellate cells against hydrogen peroxide-induced cell death. Biochim Biophys Acta 1832: 2027-2034, 2013.

28. Iversen R, Andersen PA, Jensen KS, Winther JR and Sigurskjold BW: Thiol-disulfide exchange between glutaredoxin and glutathione. Biochemistry 49: 810-820, 2010.

29. Kumar C, Igbaria A, D'Autreaux B, Planson AG, Junot C, Godat E, Bachhawat AK, Delaunay-Moisan A and Toledano MB: Glutathione revisited: A vital function in iron metabolism and ancillary role in thiol-redox control. EMBO J 30: 2044-2056, 2011.

30. Schoeneberger H, Belz K, Schenk B and Fulda S: Impairment of antioxidant defense via glutathione depletion sensitizes acute lymphoblastic leukemia cells for Smac mimetic-induced cell death. Oncogene 34: 4032-4043, 2015.

31. Buşu C, Li W, Caldito G and Aw TY: Inhibition of glutathione synthesis in brain endothelial cells lengthens S-phase transit time in the cell cycle: Implications for proliferation in recovery from oxidative stress and endothelial cell damage. Redox Biol 1: 131-139, 2013.

32. Hall MD, Marshall TS, Kwit AD, Miller Jenkins LM, Dulcey AE, Madigan JP, Pluchino KM, Goldsborough AS, Brimacombe KR, Griffiths GL, et al: Inhibition of glutathione peroxidase mediates the collateral sensitivity of multidrug-resistant cells to tiopronin. J Biol Chem 289: 21473-21489, 2014. 